with some chemical effects in irradiated meat (G. M. Wilson). These contributions indicated that the theories of radiation chemistry are still far from adequate to explain the changes in such complex systems as foods. As R. S. Hannan pointed out, in nearly all cases, the easiest approach to a particular problem is an experimental one. In the micro. biological field there is obviously need for more information on how micro-organisms behave on irradiation, and particularly on the behaviour of those organisms which survive irrediation. If, ultimately, the idea of processing food with radiation is not exploited, the results of such researches as that of the Quartermaster Corps of the U.S. Army on the properties of packaging materials will be of great value to the food industry.

It will still be necessary to show that irradiated foods are acceptable from the medical point of view, even if the process is considered useful to the food industry and the consumer. To yield information on this topic, animal feeding studies are being conducted at the Wantage Radiation Laboratory, and T. Horne gave details of these, and the plans for future work. The very careful and large-scale experiments being conducted by the Office of the Surgeon General of the U.S. Army should also be extremely valuable. To date, the tests have failed to show any harmful effects through eating irradiated foods. Some destruction of vitamins by irradiation has been noted but, in general, losses are no greater than with most other methods of food processing.

The symposium confirmed the impression that has been growing for some time, that radiation processing is unlikely to displace conventional methods of preservation. It does seem, however, that it will be a useful additional method, and there are clearly some applications of considerable potential use where it has special advantages. But, even with these, there still remains much more research to be done before the process can be exploited commercially.

A fuller account of this symposium is available on application to the Superintendent, Low Temperature Research Station, Downing Street, Cambridge (L.T.R.S. Memorandum 312).

This article has been prepared as part of the programme of the Food Investigation Organization of the Department of Scientific and Industrial Research. B. Coleby

\title{
OBITUARIES
}

\section{Prof. R. M. Davies}

Rhistart Morgan Davies, professor of physics in the University College of Wales, Aberystwyth, died suddenly on February 18, a fortnight after his fiftyfifth birthday.

His death terminates one of the most interesting careers in the British university world. $\mathrm{He}$ was a native of the quarrying village of Corris, Merionethshire, and received his early education at the village school and at the grammar school at Dolgelley, where his scientific potentialities were recognized by Dr. John Griffith, one of the most remarkable of Welsh headmasters. In 1921 he entered the College at Aberystwyth, where he was destined to spend virtually the whole of his university career. $\mathrm{He}_{\Theta}$ graduated with first-class honours in 1924, and was appointed assistant lecturer in 1925 .

His research career may be said to have commenced at the Admiralty Signal School at Portsmouth, where he spent the summer of 1925 and where he was introduced to quartz crystals and piezoelectricity. On his appointment to the staff at Aberystwyth he entered upon a research programme on the elastic properties of Rochelle salt erystals, as determined both statically and dynamically. The eircuitry of this problem led him to digress, at the instigation of a chemical colleague, into a determination of the absolute dielectric constant of pure benzene at low radio-frequencies; he also developed two types of moisture meter for use with granular materials, one of which was marketed commercially.

These various research projects were pursued with characteristic vigour and determination, and gained him in succession the M.Sc. and D.Se. degrees of his University. An opportunity to devote his whole time and energy to research, and in particular to his early field of interest, elasticity, came in 1939 with the award of a Leverhulme Research Fellowship, with which he proceeded to Cambridge to work with Sir Geoffrey Taylor.
Sir Geoffrey soon recognized in him not only one of the few academic physicists interested in the mechanical properties of materials, but also one who was, in addition, gifted with a penetrating mind, experimental skill of a high order, and an infinite capecity for hard work. The association of the two men, started in 1939, persisted through the years; it produced, during the war period, a wealth of results, embodied in official reports, which were of the greatest value in the war effort, both in attack and in defence, and it was later to inspire much of the work of the research school which Davies established at Aberystwyth, whither he returned in 1945 and where he was appointed professor in 1946 .

The research work at Aberystwyth was concerned with transient stresses and the propagation of stress waves in solids, and with detonation pressures and shock waves in gases. Much of this work arose from Davies's investigation, carried out in Cambridge and published in the Transactions of the Royal Society in 1948, of the Hopkinson pressure bar, originally devised in 1914 and largely neglected. The resurrection of the pressure bar as a modern instrument of research into transient high-pressure phenomena was typical of Davies's flair for rediscovering nearforgotten techniques; he had read deeply in the classical researches of the past, and nothing gave him more pleasure than to revive, from some forgotten paper by Kelvin or Rayleigh or Reynolds, some argument relevant to a modern problem.

The nature of this extensive research programme, of a type rare in British universities, inevitably brought to Aberystwyth many visitors from many lands, and to Davies himself many invitations to address conferences and symposia, and to join technical committees of various Ministries. In this way he very greatly enlarged his field of activity and became widely known as one of the leading authorities in his particular subject.

In 1956 he was invited to accept a visiting professorship at the California Institute of Technology 
at Pasadena. During seven months in the United States he visited many American universities and research institutes and delivered numerous discourses; in quite characteristic fashion, he scorned American public transport, and drove his own car, acquired in New York on his arrival and disposed of there on his departure, across the American continent, over a total distance of 16,000 miles. Shortly after his return, Davies was again invited to visit the United States, to address the annual meeting of the American Institute of Mining and Metallurgical Engineers, held in New York in February this year ; he had agreed to do so, and to visit other centres to renew contacts made during the previous year, but he died during the week of the meeting.

Research, though energetically and enthusiasticelly pursued, by no means represented the sum total of his activity. He was a tescher of unusual quality, and his lectures were invariably prepared with meticulous care and presented with superb lucidity. $\mathrm{H}_{\Theta}$ was, in addition, a gifted administrator; his department was most efficiently organized, and he was, for a period, vice-principal of his College. $\mathrm{He}$ had also numerous other interests quite unconnected with his academic work. He was an accomplished musician with a particular interest in church music, and was organist and choirmaster in his own church at Aberystwyth and at the church which he attended at Cambridge; he had in his early years been an active cross-country runner and retained throughout a lively interest in all kinds of sport, his last hobby being yachting; and in his rare moments of relaxation, he was an avid reader of detective fiction.

In all the many facets of his life, he had an essential good-nature and personal charm which brought him a host of friends, varying immensely among themselves, but united by their regard for his warm humanity and patent sincerity. The key to his character undoubtedly lay in the fact that his roots remained firmly fixed in his native Welsh soil, and he carried into the wide world the virtues implanted in him by the devout, unhurried and unpretentious atmosphere of his upbringing.

$$
\text { I. C. JoNes }
$$

THe sad news of Prof. R. M. Davies's sudden death came as a shock to his many friends in the United States. He had been invited to lecture at the American Institute of Mining and Metallurgical Engineers Symposium on High-Speed Stressing of Solids in New York City on February 17. It was with great disappointment that we heard that, due to illness, it was necessary for him to cancel that visit.

He had been in the United States twice, once during the Second World War and again for the academic year $1956-57$, when he was a visiting professor and lectured at the California Institute of Technology and at Rensselaer Polytechnic Institute. During this last visit, in addition, in his travel from coast to coast, he gave lectures at various universities and technical institutes.

Prof. Davies was a superb teacher, and all those who had the fortune to attend his lectures will never forget the excellence and brilliance of his presentation. As a result of his research, especially in the field of stress waves in solids, he leaves important and permanent contributions.

Those who knew R. M. Davies during the Second World War, when he was working under Sir Geoffrey Taylor at Cambridge for the Ministry of Supply, will always remember the very happy combination of 'G. I.' and 'R. M.'. His loss is particularly felt by the many who enjoyed his friendship and appreciated his warm personality, his deep Welsh sense of humour and the interest, helpfulness and understanding he always showed toward other people. These friends will reslize that with the passing of $R$. M. Davies a very dear part of their lives has forever ended.

ENRICO VOLTERRA

\section{Prof. T. Shimizu}

Tayei Shrmizu, who died suddenly on January 30 , was well known as the founder of the chief Japanese school of studies on steroids and especially bile acids. He was a pupil of the late Heinrich Wieland from 1920 until 1923, and again from 1929 until 1931, and from him returned to Japan with an enthusiasm in this field which proved lifelong.

Shimizu was born in Tokyo in 1889 and graduated from Kyoto University Medical School in 1915. He began his studies on bile acids there, under the late Prof. T. Araki. After his return from Germany in 1923, Shimizu was appointed professor of biochemistry at Okayama Medical School : he became president of this School in 1949 and, in 1952, president of Okayama University. He was elected a member of the Japan Academy in 1950, and in 1951 a member of the German Academy of Sciences.

Much of Shimizu's scientific contribution consisted in the persistence and skill with which he and his pupils followed up the observation of Hammarsten (1898), who found the steroid alcohol, scymnol, in the bile of sharks. This ought, perhaps, to have stimulated a much wider search for unusual bile salts, but it was not until Shimizu began his work that such a search was seriously undertaken. It was then pursued with remarkable zeal : for example, 4,000 toads were used to collect 5 litres of bile; from this were obtained interesting alcohols, finally carefully described by $\mathbf{T}$. Kazuno (Hoppe-Seylers Z., 266, I1; 1940) and the bile acids trihydroxysterocholenic and trihydroxyisosterocholenic, $\mathrm{C}_{22} \mathrm{H}_{46} \mathrm{O}_{8}$, characterized by Shimizu and T. Oda (Hoppe-Seylers $Z$., 227, 74; 1934), and by Shimizu and T. Kazuno (Hoppe-Seylers $Z$., 239, 67 ; 1936). In later work, Y. Okasaki $(J$. Biochem. Tokyo, 36, 65, 77 ; 1944) collected $1 \cdot 5$ litres of bile from 100,200 specimens of a newt, Diemyctylus phyrrhogaster. An account of the work of Shimizu's school up to 1935 was included by him in a comprehensive book ("Utber die Chemie und Physiologie der Gallensäuren", Muramato, Okayama, 1935), which he dedicated to Prof. Araki on his seventieth birthday. K. Ohta (Hoppe-Seylers $Z ., 259,53$; 1939) reviewed the work at Okayama on fish bile, and later writers have summarized the Japanese contributions up to 1955 (for example, Physiol. Rev., 35, 178; 1955).

The discoveries of Shimizu and his pupils have widened greatly the scope of chemical and physiological study of bile salts, and have stimulated a new awareness of the interest of biochemical species comparisons in this as in other fields.

In June 1957 Shimizu paid his last visit to Wieland, and also visited England for the first time for nearly forty years. He then, in spite of an indifferent command of English, read a paper on some of the work now being done by one of his former pupils, S. Hayakawa. He spent some time in the United States before returning to Japan.

Tayei Shimizu was a man of broad vision, good humour and modesty of character. His memory is held in affection by his friends and former pupils everywhere. $\quad$ G. A. D. Haslewood 